\title{
An Alternative Regression-Based Approach to Estimate the Crash Modification Factors of Multiple Treatments Using Before-and-After Data
}

\author{
Uditha Galgamuwa*, Sunanda Dissanayake \\ Department of Civil Engineering, Kansas State University, Manhattan, KS, USA \\ Email: *galgamuwa@ksu.edu, sunanda@ksu.edu
}

How to cite this paper: Galgamuwa, U. and Dissanayake, S. (2018) An Alternative Regression-Based Approach to Estimate the Crash Modification Factors of Multiple Treatments Using Before-and-After Data. Journal of Transportation Technologies, $\mathbf{8}$, 273-290.

https://doi.org/10.4236/jtts.2018.84015

Received: August 29, 2018

Accepted: October 15, 2018

Published: October 18, 2018

Copyright $(9) 2018$ by authors and Scientific Research Publishing Inc. This work is licensed under the Creative Commons Attribution International License (CC BY 4.0).

http://creativecommons.org/licenses/by/4.0/

\begin{abstract}
Before-and-after methods have been effectively used in the road safety studies to estimate Crash Modification Factors (CMFs) of individual treatments as well as the multiple treatments on roadways. Since the common practice is to apply multiple treatments on road segments, it is important to have a method to estimate CMFs of individual treatment so that the effect of each treatment towards improving the road safety can be identified. Even though there are methods introduced by researchers to combine multiple CMFs or to isolate the safety effectiveness of individual treatment from CMFs developed for multiple treatments, those methods have to be tested before using them. This study considered two multiple treatments namely 1) Safety edge with lane widening 2) Adding $2 \mathrm{ft}$ paved shoulders with shoulder rumble strips and/or asphalt resurfacing. The objectives of this research are to propose a regression-based method to estimate individual CMFs estimate CMFs using before-and-after Empirical Bayes method and compare the results. The results showed that having large sample size gives accurate predictions with smaller standard error and p-values of the considered treatments. Also, results obtained from regression method are similar to the EB method even though the values are not exactly the same. Finally, it was seen that the safety edge treatment reduces crashes by $15 \%-25 \%$ and adding $2 \mathrm{ft}$ shoulders with rumble strips reduces crashes by $25 \%-49 \%$.
\end{abstract}

\section{Keywords}

Crash Modification Factors for Multiple Treatments, Negative Binomial Models, Safety Edge Treatments, Paved Shoulders, Empirical Bayes Method 


\section{Introduction}

Motor traffic injuries are one of the predominant causes of fatalities in the world as well as in the United States [1] [2]. More than 32,000 fatalities per year have been reported in the United States from 2009 to 2014 [3]. Furthermore, it was identified that the lane-departure crashes account for approximately $54 \%$ of the total motor vehicle fatalities in the United States. Similar to the national level, Kansas has experienced more than 350 motor vehicle fatalities per year from 2009 to 2014 and nearly $60 \%$ of those are due to lane-departure crashes [4]. Therefore, many different treatments have been implemented on Kansas road segments such as lane widening, adding paved shoulders, rumble strips, safety edge treatments, chevrons, and cable median barriers to reduce lane-departure crashes as well as all crashes. This research estimates safety effectiveness of two treatments; safety edge treatments and adding $2 \mathrm{ft}$ paved shoulders on Kansas rural two-lane road segments where the date of implementation of those treatments are known. However, those treatments were implemented with some other treatments. Therefore, the efforts have been made to isolate the safety effectiveness of individual treatments.

Crash Modification Factors (CMFs) were used to estimate the safety effectiveness of the considered treatments. Before-and-after studies such as Empirical Bayes (EB) method have been proven to be effective in estimating CMFs of the treatments where the date of implementation is known, yet those methods would estimate the combined CMFs if the considered road segments had multiple treatments. Even though, the relationships between individual treatments and the combined treatments have been investigated it is difficult to find the exact relationship between those treatments for a given region due to differences in various factors affecting crashes. Therefore, an alternative regression-based method was introduced in this study. Generalized Linear Regression modeling with Negative Binomial error structure was used to fit the regression models using before and after data. Furthermore, before-and-after EB method was used to estimate CMFs for multiple treatments. Commonly used methods of estimating combined CMFs due to multiple treatments using individual CMFs were used to isolate the safety effectiveness of safety edge treatments and adding $2 \mathrm{ft}$ paved shoulders. Finally, results from both models were compared and the advantages and limitations are discussed in the results and conclusions.

\section{Literature Review}

Different methods have been used by researchers to develop CMFs, and many of those methods are summarized in the Highway Safety Manual [5]. These methods can be divided into two broad categories, namely before-and-after and cross-sectional study approaches. The major difference between those two approaches is that in before-and-after approach data are required for both before-and-after periods of the treatment. Therefore the date of implementation of the treatment is required. In cross-sectional studies, the date of implemen- 
tation of the treatment is not required so that the method can be used to estimate CMFs in situations where the date of implementation is not known [5]. Out of the many methods of estimating CMFs using before-and-after data, EB method is proven to provide accurate results by accounting for the regression-to-the-mean effect [6] [7] [8] [9]. However, if the road segment had multiple treatments at the same time, EB method usually estimates the combined CMF due to multiple treatments.

\subsection{Predicting CMFs for Multiple Treatments}

Many methods have been introduced in the past to combine individual crash modification factors to predict combined safety effectiveness due to multiple treatments. Same methods can be used to estimate CMFs of one treatment if the CMFs of the combined treatments and the other individual treatments are known. Following are few of the commonly used approaches that have been utilized to combine individual CMFs to estimate the safety effectiveness due to multiple treatments [5] [10] [11] [12].

- Organize CMFs based on crash types and their applications into groups.

- Previous experience and expert judgment.

- Apply a weightage factor to a multiplication of CMFs.

- Assume independence between the treatments and take the product of all the CMFs.

- Apply only the most effective CMF.

However, any of these methods haven't been proven to be effective in all the regions. Therefore each method should be tested before applying the methods in another region other than the regions that they have been proven to be effective.

\subsection{Past Studies on Considered Treatments}

Since this study tries to estimate combined CMFs due to safety edge treatments with lane widening and adding $2 \mathrm{ft}$ paved shoulders with asphalt resurfacing and/or shoulder rumble strips and the individual CMF due to safety edge, lane widening, adding $2 \mathrm{ft}$ paved shoulder, asphalt resurfacing and adding shoulder rumble strips, previous literature on those treatments were considered so that the results can be compared with other studies.

\subsubsection{Safety Edge Treatment}

Safety edge enables drivers to safely re-enter into the travel lane who drifted off the highway [13]. It has been proven to reduce all crashes, run-off-road crashes, and pavement drop of crashes in many states including Iowa [14]. A study conducted in Iowa using before-and-after EB method showed that implementing safety edge treatment reduced all non-intersection crashes by $13 \%$ and fatal and injury crashes by $16 \%$. Also, it was found that due to safety edge treatments total run-off-road (ROR) crashes were reduced by $12 \%$ and the injury ROR crashes decreased by $8 \%$ [15]. However, a study conducted in Georgia, Indiana, and New York using EB method and cross-sectional method showed the mixed ef- 
fects due to implementing safety edge treatments on two-lane road segments. Results obtained from EB method for Georgia and Indiana showed that having safety edge treatments reduced total crashes and fatal and injury crashes up to $11 \%$ and $44 \%$, total ROR crashes and fatal and injury ROR crashes up to $14 \%$ and $46 \%$ and drop off related all crashes and fatal and injury crashes up to $10 \%$ and $38 \%$. Cross-sectional study showed that having safety edge treatments on two-lane roads in Georgia, Indiana, and New York reduced total crashes and fatal and injury crashes up to $48 \%$ and $70 \%$, total ROR crashes and fatal and injury ROR crashes up to $57 \%$ and $81 \%$ and drop off related all crashes and fatal and injury crashes up to $70 \%$ and $86 \%$. However, it was seen that in the cross-sectional method the standard error of the safety edge treatments had larger values than in EB method [16].

\subsubsection{Increasing Lane Width}

Having larger lane widths in the past studies have shown both crash reduction and crash increase effect. A study conducted in Indiana showed that increasing lane width associated with fewer crashes on rural two-lane roads [17]. However, literature also revealed that having larger lane widths have a positive association with crashes. In a study conducted in Florida, $10 \mathrm{ft}$ lane width instead of $12 \mathrm{ft}$ lanes reduced $42 \%$ of all crashes on rural multilane roads and $27 \%$ on rural two-lane roads. Also, the same study showed that having $11 \mathrm{ft}$ lane widths instead of $12 \mathrm{ft}$ lane reduced $24 \%$ of crashes on rural multilane roads and $15 \%$ crashes on rural two-lane roads in Florida [18].

\subsubsection{Adding Paved Shoulders}

Literature indicated that adding paved shoulders have both crash reduction and increasing effect on two-lane and four-lane road segments. A study conducted in Kansas using cross-sectional method showed that having $2 \mathrm{ft}$ paved shoulders reduce lane-departure crashes by $12 \%-18 \%$ and $11 \%-34 \%$ on the rural undivided the tangent and curved road segments respectively. Also, the study showed that having $2 \mathrm{ft}$ paved shoulders reduce fatal and injury lane-departure crashes by $6 \%-16 \%$ and $7 \%-21 \%$ on a tangent and curved road segments in Kansas [19]. Even though there is much literature indicated that the paved shoulders reduce crashes, there are few which conclude that the paved shoulders are positively associated with crashes. A study conducted in Illinois estimated the safety effectiveness of adding and widening paved shoulders on rural multilane and two-lane road segments. The results showed that widening paved shoulders from 4 and $6 \mathrm{ft}$ to $8 \mathrm{ft}$ increased shoulder related fatal crashes by $4 \%-7 \%$ and reduced injury crashes by $3 \%-7 \%$. Also, the study showed that adding $6 \mathrm{ft}$ or $8 \mathrm{ft}$ paved shoulders have increased shoulder related fatal crashes by $8 \%-10 \%$ and injury crashes by $5 \%-8 \%[20]$.

\subsubsection{Asphalt Resurfacing}

Asphalt resurfacing is done to improve the road condition and to increase the serviceability of the road. Same as for many other treatments, asphalt resurfacing 
showed both negative and positive impacts on the crashes. A study conducted in Florida showed that resurfacing multi-lane roadways increased total crashes by $1 \%$ while reducing severe crashes by $5 \%$ and rear-end crashes by $1 \%$ [21]. Another study conducted in York, Canada showed that refinish pavement with resurfacing treatment reduced all crashes by $14 \%-26 \%$, where AADT is less than 7000 vehicles per day (vpd) but has an increasing effect of $6 \%$ on the roads with AADT greater than 7000 vpd [22].

\subsubsection{Shoulder Rumble Strips}

Shoulder rumble strips are placed to alert the drivers who are likely to leave the travel lanes. Currently, the shoulder rumble strips are used in most of the rural highways as a countermeasure to reduce drift-off-roadway crashes [23]. A study conducted in Florida for rural multi-lane highways showed that having shoulder rumble strips reduced all crashes by $24 \%-35 \%$, fatal and injury crashes by $36 \%-40 \%$, single-vehicle ROR (SVROR) by $30 \%-35 \%$ and fatal and injury SVROR by $31 \%-48 \%$ [11]. A study conducted in Kansas showed that the shoulder rumble strips reduced lane-departure crashes by $6 \%-15 \%$ on rural two-lane undivided road segments, but have a mixed effect of $-25 \%-5 \%$ in curved road segments. However, the results of the same study showed that shoulder rumble strips have crash reduction effect of $5 \%-10 \%$ and $6 \%-19 \%$ on fatal and injury lane-departure crashes on the rural two-lane tangent and curved road segments [19].

\section{Data and Methodology}

This section sumerises how the data were prepared for the proposed regression based method and the EB method. Furthermore, this section sumerises methodology of estimating CMFs based on both methods.

\subsection{Data}

Crash related information including the location of the crash, crash year, and the severity was obtained from Kansas Crash Analysis and Reporting System (KCARS) database and the geometric and traffic related characteristics of before and after periods of the treatments on each road segment were extracted from Control Section Analysis System (CANSYS), which is the Kansas state highway system database. Three years before and three years after data were extracted for the considered treatments excluding the year of the treatment. Three roads were identified as having safety edge treatment with lane widening with the total length of 72 miles. Twelve roads were identified to have adding $2 \mathrm{ft}$ paved shoulder treatment with asphalt resurfacing and/or shoulder rumble strips with the total length of 461 miles.

Road segments with safety edge and lane widening treatment experienced 42 crashes and 7 fatal and injury crashes in before period, 29 crashes and 7 fatal and injury crashes in after period. Furthermore, those road segments experienced 12 lane-departure crashes and 6 fatal and injury lane-departure crashes in before 
period, 17 lane-departure crashes and 3 fatal and injury lane-departure crashes in after period. Road segments which had adding $2 \mathrm{ft}$ paved shoulders with asphalt resurfacing and/or shoulder rumble strips experienced 674 crashes and 150 fatal and injury crashes in before period, 655 crashes and 146 fatal and injury crashes in after period. Furthermore, those segment experienced 186 lane-departure crashes and 72 fatal and injury lane-departure crashes in before period, 187 lane-departure crashes and 75 fatal and injury lane-departure crashes in after period.

\subsection{Regression Method Using Before-and-After Data}

\subsubsection{Data Preperation}

Figure 1 illustrates the data preperation for the proposed method using hypothetical example which assumed that the considered road segment had road resurfacing and $2 \mathrm{ft}$ paved shoulders with shoulder rumble strips.

As shown in Figure 1, before the treatments have been applied the road segments did not have $2 \mathrm{ft}$ paved shoulders, shoulder rumble strips or asphalt resurfacing. Therefore, those variable in the before period is zero as shown in Figure 1 (b), route number 1a. However, the considered road segment had all the treatmnets at the same time. Therefore, the corresponding values for those treatment variables are one, as shown in Figure 1(b), route number 1b. Segment length remains the same since the same road segment was considered, however, AADT and number of lane-departure crashes were varied as shown in Figure $1(\mathrm{~b})$, route number $1 \mathrm{a}$, and $1 \mathrm{~b}$. Since the before and after characteristics of the same road segment was considered the effect of not considering the driver behaviour and environmental-related characteristics in the SPF in EB method can be minimized.

\subsubsection{Model Development}

A generalized linear regression model using Negative Binomial error structure was employed to develop models to estimate individual effect of each treatment. Equation 1 shows the general form of the negative binomial regression model which is modified for the crash frequency modeling [24] [25].

$$
\ln y=X \beta+\varepsilon_{i}
$$

where,

$$
y=n \times 1 \text { observations of crashes; }
$$

$\beta=\mathrm{p} \times 1$ vector of estimated regression parameters corresponding to geometric design and traffic volume related independent variables;

$X=n \times \mathrm{p}$ known independent model matrix of geometric design and traffic volume related variables;

$\varepsilon_{i}=n \times 1$ random vector variables (error).

The mean-variance relationship of negative binomial distribution can be expressed as shown in Equation (2).

$$
\operatorname{Var}(y)=E(y)+k E(y)^{2}
$$




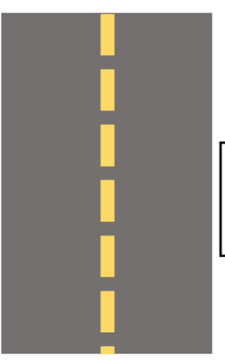

(a)

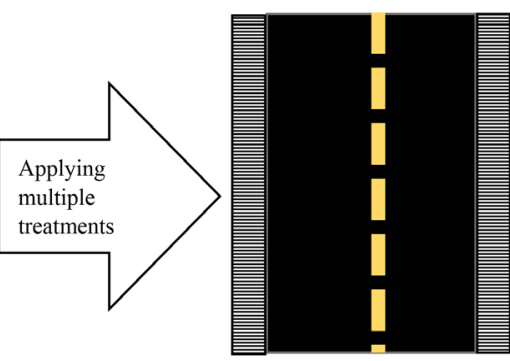

(b)

\begin{tabular}{|c|c|c|c|c|c|c|c|c|c|}
\hline \multicolumn{10}{|c|}{ Before and After Attributes of Route Number 1} \\
\hline \multirow{2}{*}{$\begin{array}{l}\text { Route } \\
\text { No }\end{array}$} & \multirow{2}{*}{$\begin{array}{l}\text { Segment } \\
\text { Length }\end{array}$} & \multicolumn{4}{|c|}{ Before (a) } & \multicolumn{4}{|c|}{ After (b) } \\
\hline & & AADT & $\begin{array}{l}\text { 2ft Paved } \\
\text { Shoulders }\end{array}$ & $\begin{array}{c}\text { Shoulder } \\
\text { Rumble } \\
\text { Strips }\end{array}$ & $\begin{array}{c}\text { Asphalt } \\
\text { Resurfacing }\end{array}$ & AADT & $\begin{array}{l}\text { 2ft Paved } \\
\text { Shoulders }\end{array}$ & $\begin{array}{c}\text { Shoulder } \\
\text { Rumble } \\
\text { Strips }\end{array}$ & $\begin{array}{c}\text { Asphalt } \\
\text { Resurfacing }\end{array}$ \\
\hline 1 & 0.5 & 2,500 & No & No & No & 2,600 & Yes & Yes & Yes \\
\hline
\end{tabular}

(a)

Considered as route number 1a

Considered as route number $1 \mathrm{~b}$

\begin{tabular}{|l|l|l|l|l|l|l|}
\hline $\begin{array}{l}\text { Route } \\
\text { Number }\end{array}$ & $\begin{array}{l}\text { Segment } \\
\text { Length }\end{array}$ & AADT & $\begin{array}{l}\text { 2ft Paved } \\
\text { Shoulders }\end{array}$ & $\begin{array}{l}\text { Shoulder } \\
\text { Rumble } \\
\text { Strips }\end{array}$ & $\begin{array}{l}\text { Asphalt } \\
\text { Resurfacing }\end{array}$ & $\begin{array}{l}\text { Number } \\
\text { of } \\
\text { Crashes }\end{array}$ \\
\hline $1 \mathrm{a}$ & 0.5 & 2,500 & 0 & 0 & 0 & 5 \\
\hline $2 \mathrm{a}$ & 0.2 & 2,000 & 0 & 0 & 0 & 4 \\
\hline $3 \mathrm{a}$ & 0.6 & 3,500 & 0 & 0 & 0 & 6 \\
\hline $4 \mathrm{a}$ & 0.3 & 2,750 & 0 & 0 & 0 & 3 \\
\hline $5 \mathrm{a}$ & 0.25 & 2,850 & 0 & 0 & 0 & 1 \\
\hline $6 \mathrm{a}$ & 0.9 & 2,400 & 0 & 0 & 0 & 6 \\
\hline $\mathrm{lb}$ & 0.5 & 2,600 & 1 & 1 & 1 & 3 \\
\hline $2 \mathrm{~b}$ & 0.2 & 2,100 & 1 & 1 & 0 & 2 \\
\hline $3 \mathrm{~b}$ & 0.6 & 3,600 & 1 & 1 & 1 & 4 \\
\hline $4 \mathrm{~b}$ & 0.3 & 2,850 & 1 & 0 & 0 & 0 \\
\hline $5 \mathrm{~b}$ & 0.25 & 2,950 & 1 & 0 & 1 & 0 \\
\hline 6b & 0.9 & 2,500 & 1 & 1 & 1 & 5 \\
\hline
\end{tabular}

Geometric and trafficrelated characteristics of

before time period with crashes

Geometric and trafficrelated characteristics of after time period with crashes

(b)

Figure 1. Hypothetical example of data preparation for proposed regression based method.

where,

$\operatorname{Var}(y)=$ variance of observed crashes;

$E(y)=\mu=$ expected crash frequency;

$k=$ overdispersion parameter.

The maximum likelihood method estimates the coefficients in the linear regression model and the maximum likelihood function $L\left(y, x, \beta, \sigma^{2}\right)$ is shown in Equation (3) [26].

$$
L\left(y, x, \beta, \sigma^{2}\right)=\frac{1}{\left(2 \pi \sigma^{2}\right)^{n / 2}} \exp \left[-\frac{1}{2 \sigma^{2}} \sum_{i=1}^{n}(y-\mu)^{2}\right]
$$

When developing models for the road segments with safety edge treatment and lane widening, crashes per year per segment were considered as the response variable. Access control, terrain type, segment length, posted speed limit, the percentage of heavy vehicles, AADT, average lane width, and presence of safety edge treatment were considered as explanatory variables. Similarly, crashes per year per segment were considered as the response variable when developing models for adding $2 \mathrm{ft}$ paved shoulders with asphalt resurfacing and/or shoulder 
rumble strips. Segment length, access control, average lane width, terrain type, posted speed limit, the percentage of heavy vehicles, AADT, the presence of $2 \mathrm{ft}$ paved shoulders only, presence of $2 \mathrm{ft}$ paved shoulders with shoulder rumble strips and asphalt resurfacing were considered as the explanatory variables. When developing both models influence points were identified using DFBETAS, which indicates how much influence does one observation has in the determination of particular regression coefficient [27].

\subsection{Before-and-After EB Method}

The same dataset used to develop regression models was used to estimate CMFs using EB method. Since all the road segments with considered treatments are on rural two-lane undivided road segments, safety performance function given in HSM was used to predict average crash frequencies determined for base conditions on the respective road segment in before and after period as shown in Equation (4). Since it was decided to develop CMFs for all crash types and lane-departure crashes, the proportion of lane-departure crashes to the all crashes were calculated using reference sites. Also, proportions of fatal crashes to all crashes were calculated so that these models can be used to predict lane-departure crashes as well as fatal and injury crashes. When selecting reference sites, variables such as access control, lane width, shoulder type, shoulder width, rumble strips, posted speed limit, AADT and percentage of heavy vehicles were used. Equation (5) was used to predict average crash frequency for a specific year after calibrating SPF for the local conditions using the calculated calibration factors and Equation 6 was used to estimate the expected number of crashes during before period [5] [8].

$$
N_{s p f r s}=A A D T_{i} \times L_{i} \times 365 \times 10^{(-6)} \times \mathrm{e}^{(-0.312)}
$$

where,

$N_{s p f r s}=$ Predicted average crash frequency for base conditions using a statistical regression model;

$A A D T=$ Annual average daily traffic (vehicles/day) on road segments $i$;

$L_{i}=$ Length of roadway segment $i$ (miles).

$$
N_{\text {predicted }}=N_{s p f x} \times\left(\mathrm{CMF}_{1 x} \times \mathrm{CMF}_{2 x} \times \cdots \times \mathrm{CMF}_{y z}\right) \times C_{x}
$$

where,

$N_{\text {predicted }}=$ Predicted average crash frequency for a specific year for site type $x$,

$N_{s p f x}=$ Predicted average crash frequency determined for base conditions of the SPF developed for site type $x$,

$\mathrm{CMF}_{2 x}=$ Crash modification factors specific to SPF for site type $x$, and

$C_{x}=$ Calibration factor to adjust SPF for local conditions for site type $x$.

$$
N_{\text {expected }, T, B}=w_{i} N_{\text {predicted }, T, B}+\left(1-w_{i}\right) N_{\text {observed }, T, B}
$$

where,

$N_{\text {expected }, T, B}=$ Expected crash frequency without safety edge/adding $2 \mathrm{ft}$ paved shoulder treatment; 
$N_{\text {predicted, } T, B}=$ Predicted crash frequency estimated using Equation (5);

$N_{\text {observed }, T, B}=$ Observed crash frequency in the before period;

$w_{i}=$ Weight factor based on overdispersion parameter and the predicted crash frequencies in before period.

Finally, CMFs were calculated using the expected number of crashes in after period and the observed crash frequencies.

\subsection{Estimating CMFs for Individual Treatments}

Three of the commonly used methods were identified to estimate combined effect of treatments using their individual CMFs as shown in Equation (7), (8) and (9) [5] [11] [12].

Method 1: Assume Independence of Treatment

$$
\mathrm{CMF}_{\mathrm{CT}}=\mathrm{CMF}_{1} \times \mathrm{CMF}_{2} \times \cdots \times \mathrm{CMF}_{n}
$$

where,

$\mathrm{CMF}_{\mathrm{CT}}=\mathrm{CMF}$ of combined treatments;

$\mathrm{CMF}_{1}=\mathrm{CMF}$ of $1^{\text {st }}$ treatment;

$\mathrm{CMF}_{2}=\mathrm{CMF}$ of $2^{\text {nd }}$ treatment;

$\mathrm{CMF}_{n}=\mathrm{CMF}$ of $n^{\text {th }}$ treatment.

Method 2: Systematic Reduction of Safety Effect of Less Effective Reduction

$$
\mathrm{CMF}_{\mathrm{CT}}=\mathrm{CMF}_{1} \times \mathrm{CMF}_{2, \text { Reduced }}
$$

where,

$\mathrm{CMF}_{\mathrm{CT}}=\mathrm{CMF}$ of combined treatments;

$\mathrm{CMF}_{1}=\mathrm{CMF}$ of $1^{\text {st }}$ treatment.

$\mathrm{CMF}_{2, \text { Reduced }}=\frac{1-\mathrm{CMF}_{2}}{2}+\mathrm{CMF}_{2} ; \mathrm{CMF}_{2}$ is the less effective treatment.

Method 3: Multiply by Weighted Factor

$$
C \mathrm{MF}_{C T}[\text { Turner Method }]=1-\left[\frac{2}{3}-\left(1-\left(\mathrm{CMF}_{1} \times \mathrm{CMF}_{2}\right)\right)\right]
$$

where;

$\mathrm{CMF}_{C T}=\mathrm{CMF}$ of combined treatments;

$\mathrm{CMF}_{1}=\mathrm{CMF}$ of $1^{\text {st }}$ treatment;

$\mathrm{CMF}_{2}=\mathrm{CMF}$ of $2^{\text {nd }}$ treatment.

Even though these methods were introduced to estimate CMFs for multiple treatments using CMFs of individual treatments, these methods can be used to estimate individual CMF if the CMF due to multiple treatments and other individual CMFs are known. Since one of the objectives of this study is to compare the CMFs obtained from regression method with the EB method, individual CMFs should be estimated using the CMFs estimated using EB method. Therefore, Equation (7), (8), and (9) were used to estimate individual CMFs using the CMFs obtained for multiple treatments using EB method. Since main focus was to identify the safety effectiveness of safety edge treatment and adding $2 \mathrm{ft}$ paved shoulders, individual CMFs were estimated for those two treatments. However, 
CMFs for other treatments such as increasing lane width, adding $2 \mathrm{ft}$ paved shoulders with shoulder rumble strips and asphalt resurfacing could not be found for Kansas two-lane rural road segments. Therefore, CMFs estimated from the regression method was used when calculating individual CMFs using previously mentioned methods.

\section{Results and Discussion}

In order to understand the main characteristics of the selected road segments, descriptive statistics of road segments were calculated and shown in Table 1 . It is seen that the roads which had safety edge treatments with lane widening are low volume roads. The roads which had $2 \mathrm{ft}$ paved shoulders with asphalt resurfacing and/or shoulder rumble strips have high traffic volumes than the roads with safety edge treatments. Segment length distribution has a wide range of the roads which had $2 \mathrm{ft}$ paved shoulders with asphalt resurfacing and/or shoulder rumble strips than in the roads with safety edge treatments.

\subsection{Regression Method to Estimate Individual CMFS}

Separate models were developed using SAS 9.4 for each combined treatment as mentioned in the methodology [28]. Results of the two models are shown in Table 2 with their standard errors and p-values.

When developing models, the variance inflation factor (VIF) was checked in both models, and it was seen that the selected variables into the models have VIF less than 5. Therefore, it was concluded that there aren't any multicollinearity effects between explanatory variables.

Based on the results presented in Table 2, it can be seen that the dispersion parameters of the Model 1 are less than 1 and in Model 2, they are greater than 1. Literature shows that the obtained values are reasonable for such models [25] [29]. However, all crashes and all lane-departure crashes may overestimate the safety effectiveness of the treatments. Also, the results showed that the p-values of the variables of interests in Model 1 are larger than in the Model 2. The reason of having larger p-values in Model 1 has a relatively smaller sample size than the Model 2. Even in the same model, it was seen that the p-values are larger in the models which were developed using fatal and injury crashes than the models developed using all crashes. Also, the results showed higher p-values for segment length variable and AADT variable which indicated that the variation of that variables in the considered time period cannot explain having variation in crash frequencies since most noticeable change on the road segments for the variation of crash frequency is due to having treatments on the respective road segments. For an example, consider Figure 1(b). However, it was seen that if the sample size is large the models give smaller $\mathrm{p}$-values for both all crashes and fatal and injury crash models as in Model 2.

Estimated regression parameters were used to develop CMFs, and $\mathrm{CMF}=$ $\exp (\beta)$ was used to back transform the estimated regression parameters to find 
Table 1. Descriptive statistics of before and after characteristics of the road segments with treatments.

\begin{tabular}{|c|c|c|c|c|c|c|}
\hline \multirow{3}{*}{ Road Name } & \multicolumn{4}{|c|}{ (a) Roads with safety edge treatments with lane widening } & & \\
\hline & \multicolumn{2}{|c|}{ Other treatments } & \multirow{2}{*}{$\begin{array}{c}\text { Data of } \\
\text { implementation }\end{array}$} & \multirow{2}{*}{$\begin{array}{c}\begin{array}{c}\text { Segment length } \\
\text { (miles) }\end{array} \\
\text { Mean (SD) }\end{array}$} & \multicolumn{2}{|c|}{$\begin{array}{c}\text { AADT } \\
\text { (vehicles per day) }\end{array}$} \\
\hline & $\begin{array}{c}\text { Lane widening } \\
12 \mathrm{ft} \text { to } 13 \mathrm{ft}\end{array}$ & $\begin{array}{c}\text { Lane widening } \\
12 \mathrm{ft} \text { to } 14 \mathrm{ft}\end{array}$ & & & $\begin{array}{l}\text { Before Mean } \\
\text { (SD) }\end{array}$ & $\begin{array}{l}\text { After Mean } \\
\quad(\mathrm{SD})\end{array}$ \\
\hline K-23 from Lane County & No & Yes & 2010 & $\begin{array}{c}1.02 \\
(1.745)\end{array}$ & $\begin{array}{c}826 \\
(501)\end{array}$ & $\begin{array}{c}884 \\
(253)\end{array}$ \\
\hline K-23 to US $83 / \mathrm{K} 383$ junction & No & Yes & 2012 & $\begin{array}{c}1.58 \\
(2.32)\end{array}$ & $\begin{array}{c}640 \\
(253)\end{array}$ & $\begin{array}{c}633 \\
(281)\end{array}$ \\
\hline K 25 from Russell Spring & Yes & No & 2012 & $\begin{array}{c}1.67 \\
(3.19) \\
\end{array}$ & $\begin{array}{l}200 \\
(18)\end{array}$ & $\begin{array}{l}234 \\
(15)\end{array}$ \\
\hline \multicolumn{7}{|c|}{ (b) Roads with adding $2 \mathrm{ft}$ paved shoulders with asphalt resurfacing and/or shoulder rumble strips } \\
\hline & \multicolumn{2}{|c|}{ Other treatments } & $\begin{array}{c}\text { Data of } \\
\text { implementation }\end{array}$ & $\begin{array}{l}\text { Segment length } \\
\text { (miles) }\end{array}$ & \multicolumn{2}{|c|}{$\begin{array}{c}\text { AADT } \\
\text { (vehicles per day) }\end{array}$} \\
\hline & $\begin{array}{l}\text { Asphalt } \\
\text { resurfacing }\end{array}$ & $\begin{array}{l}\text { Shoulder } \\
\text { rumble strips }\end{array}$ & & Mean (SD) & $\begin{array}{c}\text { Before } \\
\text { Mean (SD) }\end{array}$ & $\begin{array}{c}\text { After } \\
\text { Mean (SD) }\end{array}$ \\
\hline US-5 DK/MR Counties & Yes & No & 2013 & $\begin{array}{c}0.629 \\
(1.388)\end{array}$ & $\begin{array}{l}1.032 \\
(230)\end{array}$ & $\begin{array}{l}1.017 \\
(224)\end{array}$ \\
\hline K-156 & No & No & 2014 & $\begin{array}{c}1.195 \\
(1.535)\end{array}$ & $\begin{array}{l}1.718 \\
(495)\end{array}$ & $\begin{array}{l}1.140 \\
(374)\end{array}$ \\
\hline US-56 Counsel Groove & Yes & No & 2013 & $\begin{array}{c}0.592 \\
(1.339)\end{array}$ & $\begin{array}{l}1.859 \\
(179)\end{array}$ & $\begin{array}{l}1.752 \\
(113)\end{array}$ \\
\hline K-99 NCL of Alma & Yes & No & 2013 & $\begin{array}{l}0.4808 \\
(0.883)\end{array}$ & $\begin{array}{c}2.673 \\
(2.049)\end{array}$ & $\begin{array}{c}2.772 \\
(2.242)\end{array}$ \\
\hline US-81 & No & No & 2013 & $\begin{array}{c}0.540 \\
(0.923)\end{array}$ & $\begin{array}{l}3.759 \\
(625)\end{array}$ & $\begin{array}{l}3.971 \\
(812)\end{array}$ \\
\hline $\mathrm{K}-2 / \mathrm{K}-42$ & No & Yes & 2014 & $\begin{array}{c}0.736 \\
(1.029)\end{array}$ & $\begin{array}{c}2.421 \\
(91)\end{array}$ & $\begin{array}{c}1.555 \\
(30)\end{array}$ \\
\hline K-42 Sumner and Sedgwick Counties & No & Yes & 2012 & $\begin{array}{l}0.6131 \\
(0.451)\end{array}$ & $\begin{array}{c}3.091 \\
(34)\end{array}$ & $\begin{array}{l}3.481 \\
(119)\end{array}$ \\
\hline US-81Sumner county & No & No & 2011 & $\begin{array}{c}0.628 \\
(0.605)\end{array}$ & $\begin{array}{c}4.296 \\
(1.966)\end{array}$ & $\begin{array}{c}4.979 \\
(1.710)\end{array}$ \\
\hline K-196 Harvey county & No & Yes & 2012 & $\begin{array}{c}1.602 \\
(0.940)\end{array}$ & $\begin{array}{c}5.757 \\
(4.556)\end{array}$ & $\begin{array}{c}6.121 \\
(4.790)\end{array}$ \\
\hline K-1 Comanche county & Yes & Yes & 2013 & $\begin{array}{c}1.336 \\
(1.275)\end{array}$ & $\begin{array}{l}713 \\
(57)\end{array}$ & $\begin{array}{l}660 \\
(55)\end{array}$ \\
\hline $\mathrm{K}-130$ & No & No & 2013 & $\begin{array}{c}0.339 \\
(0.510)\end{array}$ & $\begin{array}{l}1.230 \\
(141)\end{array}$ & $\begin{array}{l}1.154 \\
(159)\end{array}$ \\
\hline US- 160 & No & Yes & 2013 & $\begin{array}{c}1.483 \\
(1.842)\end{array}$ & $\begin{array}{l}1.192 \\
(743)\end{array}$ & $\begin{array}{l}1.203 \\
(671)\end{array}$ \\
\hline
\end{tabular}

Note: SD-Standard deviation.

individual CMFs [30] [31] [32] [33] [34]. Table 3 shows the estimated CMFs due to safety edge treatment with $1 \mathrm{ft}$ lane widening and $2 \mathrm{ft}$ lane widening. Also, Table 3 shows the CMFs due to asphalt resurfacing, adding $2 \mathrm{ft}$ paved shoulders and $2 \mathrm{ft}$ paved shoulders with rumble strips.

\subsection{CMFs Estimated Using Before-and-After EB Method}

CMFs were estimated using before-and-after EB method to check whether there are similarities to the estimated CMFs using regression method. The method given in HSM was used to develop models as shown in the methodology. 
Table 2. Developed regression models to identify the crash reduction effect of individual treatments.

(a) Regression models developed for safety edge treatment (Model 1)

\begin{tabular}{|c|c|c|c|c|c|c|c|c|}
\hline \multirow{3}{*}{ Model variables } & \multicolumn{4}{|c|}{ All crash type } & \multicolumn{4}{|c|}{ Lane-departure crashes } \\
\hline & \multicolumn{2}{|c|}{ Fatal and injury } & \multicolumn{2}{|c|}{ All crashes } & \multicolumn{2}{|c|}{ Fatal and injury } & \multicolumn{2}{|c|}{ All crashes } \\
\hline & $\begin{array}{l}\text { Parameter } \\
\text { Estimates }\end{array}$ & $\begin{array}{l}\text { Standard } \\
\text { Error } \\
\text { (p-value) }\end{array}$ & $\begin{array}{l}\text { Parameter } \\
\text { Estimates }\end{array}$ & $\begin{array}{l}\text { Standard } \\
\text { Error } \\
\text { (p-value) }\end{array}$ & $\begin{array}{l}\text { Parameter } \\
\text { Estimates }\end{array}$ & $\begin{array}{l}\text { Standard } \\
\text { Error } \\
\text { (p-value) }\end{array}$ & $\begin{array}{c}\text { Parameter } \\
\text { Estimates }\end{array}$ & $\begin{array}{c}\text { Standard } \\
\text { Error } \\
\text { (p-value) }\end{array}$ \\
\hline Intercept & -8.901 & $\begin{array}{c}3.4037 \\
(0.0089)\end{array}$ & -8.176 & $\begin{array}{c}4.3537 \\
(0.0604)\end{array}$ & 18.216 & $\begin{array}{l}30.5747 \\
(0.5513)\end{array}$ & -16.039 & $\begin{array}{c}7.409 \\
(0.0304)\end{array}$ \\
\hline Safety edge & -0.243 & $\begin{array}{c}0.1521 \\
(0.1103)\end{array}$ & -0.261 & $\begin{array}{c}0.2904 \\
(0.3692)\end{array}$ & -0.154 & $\begin{array}{c}0.2934 \\
(0.6004)\end{array}$ & -0.277 & $\begin{array}{c}0.3023 \\
(0.3593)\end{array}$ \\
\hline Segment Length & 0.333 & $\begin{array}{c}0.0586 \\
(<0.0001)\end{array}$ & 0.319 & $\begin{array}{c}0.1062 \\
(0.0026)\end{array}$ & 0.223 & $\begin{array}{c}0.0949 \\
(0.0186)\end{array}$ & 0.336 & $\begin{array}{c}0.1045 \\
(0.0013)\end{array}$ \\
\hline Posted speed limit & 4.285 & $\begin{array}{c}1.359 \\
(0.0016)\end{array}$ & 0.007 & $\begin{array}{c}0.0035 \\
(0.0569)\end{array}$ & 0.521 & $\begin{array}{c}2.1276 \\
(0.8064)\end{array}$ & 5.286 & $\begin{array}{c}3.4684 \\
(0.1275)\end{array}$ \\
\hline $\mathrm{AADT}$ & 2.031 & $\begin{array}{c}0.4064 \\
(<0.0001)\end{array}$ & 2.210 & $\begin{array}{l}0.8797 \\
(0.012)\end{array}$ & 0.270 & $\begin{array}{c}0.6846 \\
(0.6929)\end{array}$ & 2.052 & $\begin{array}{l}0.8257 \\
(0.013)\end{array}$ \\
\hline Average lane width & 0.093 & $\begin{array}{c}0.0982 \\
(0.3418)\end{array}$ & 0.288 & $\begin{array}{l}0.195 \\
(0.14)\end{array}$ & 0.217 & $\begin{array}{c}0.0914 \\
(0.0178)\end{array}$ & 0.301 & $\begin{array}{c}0.1704 \\
(0.0774)\end{array}$ \\
\hline Dispersion & 0.375 & & 0.590 & & 0.352 & & 0.278 & \\
\hline
\end{tabular}

(b) Regression models developed for adding $2 \mathrm{ft}$ paved shoulders with rumble strips (Model 2)

\begin{tabular}{|c|c|c|c|c|c|c|c|c|}
\hline \multirow[b]{3}{*}{ Parameter } & \multicolumn{4}{|c|}{ All crash type } & \multicolumn{4}{|c|}{ Lane-departure crashes } \\
\hline & \multicolumn{2}{|c|}{ All crashes } & \multicolumn{2}{|c|}{ Fatal and injury } & \multicolumn{2}{|c|}{ All crashes } & \multirow[b]{2}{*}{$\begin{array}{l}\text { Parameter } \\
\text { Estimates }\end{array}$} & \multirow[b]{2}{*}{$\begin{array}{c}\text { Standard } \\
\text { Error } \\
\text { (p-value) }\end{array}$} \\
\hline & $\begin{array}{l}\text { Parameter } \\
\text { Estimates }\end{array}$ & $\begin{array}{l}\text { Standard } \\
\text { Error } \\
\text { (p-value) }\end{array}$ & $\begin{array}{l}\text { Parameter } \\
\text { Estimates }\end{array}$ & $\begin{array}{c}\text { Standard } \\
\text { Error } \\
\text { (p-value) }\end{array}$ & $\begin{array}{l}\text { Parameter } \\
\text { Estimates }\end{array}$ & $\begin{array}{l}\text { Standard } \\
\text { Error } \\
\text { (p-value) }\end{array}$ & & \\
\hline Intercept & 0.251 & $\begin{array}{c}0.3134 \\
(0.4240)\end{array}$ & -0.196 & $\begin{array}{c}0.3980 \\
(0.6232)\end{array}$ & 0.238 & $\begin{array}{c}0.3207 \\
(0.4573)\end{array}$ & -3.337 & $\begin{array}{c}2.2393 \\
(0.1362)\end{array}$ \\
\hline Segment length & 0.667 & $\begin{array}{c}0.0712 \\
(<0.0001)\end{array}$ & 0.529 & $\begin{array}{c}0.0742 \\
(<0.0001)\end{array}$ & -0.002 & $\begin{array}{c}0.0018 \\
(0.3412)\end{array}$ & 0.008 & $\begin{array}{c}0.0074 \\
(0.3017)\end{array}$ \\
\hline $\mathrm{AADT}$ & 0.158 & $\begin{array}{c}0.0441 \\
(0.0003)\end{array}$ & 0.183 & $\begin{array}{c}0.0492 \\
(0.0002)\end{array}$ & -0.073 & $\begin{array}{c}0.0497 \\
(0.1399)\end{array}$ & 0.071 & $\begin{array}{c}0.0682 \\
(0.3011)\end{array}$ \\
\hline Asphalt Resurfacing & -0.920 & $\begin{array}{c}0.1661 \\
(<0.0001)\end{array}$ & -0.947 & $\begin{array}{c}0.2356 \\
(<0.0001)\end{array}$ & 0.237 & $\begin{array}{c}0.1526 \\
(0.1209)\end{array}$ & 0.308 & $\begin{array}{c}0.2049 \\
(0.1334)\end{array}$ \\
\hline Only $2 \mathrm{ft}$ shoulders & 0.256 & $\begin{array}{c}0.1199 \\
(0.0326)\end{array}$ & 0.102 & $\begin{array}{c}0.1413 \\
(0.4709)\end{array}$ & -0.320 & $\begin{array}{c}0.1388 \\
(0.0214)\end{array}$ & -0.313 & $\begin{array}{c}0.186 \\
(0.0922)\end{array}$ \\
\hline $\begin{array}{l}2 \mathrm{ft} \text { shoulders with } \\
\text { rumble strips }\end{array}$ & -0.294 & $\begin{array}{c}0.1365 \\
(0.0311)\end{array}$ & -0.661 & $\begin{array}{c}0.1951 \\
(0.0007)\end{array}$ & -0.267 & $\begin{array}{c}0.1501 \\
(0.0758)\end{array}$ & -0.623 & $\begin{array}{c}0.2435 \\
(0.0105)\end{array}$ \\
\hline Dispersion & 2.347 & & 2.087 & & 2.336 & & 1.921 & \\
\hline
\end{tabular}

Calibration factors were calculated using the reference sites. Calibration factors for before and after periods were found to be 1.37 and 1.29. Also, the proportion of lane-departure crashes to all crash types was 0.50 and the fatal and injury crash proportions in before and after time periods were 0.24 and 0.22 . The estimated CMFs for considered multiple treatments are shown in Table 4.

Based on the results it can be seen that the CMFs estimated for safety edge treatments with lane widening are not significant except for all crashes. 
Table 3. Estimated individual CMFs using regression parameters.

(a) Model 1

\begin{tabular}{ccccc}
\hline \multirow{2}{*}{ Treatments } & \multicolumn{2}{c}{ All crash type } & \multicolumn{2}{c}{ Lane-departure crashes } \\
\cline { 2 - 5 } & All & Fatal and injury & All & Fatal and injury \\
\hline Safety edge & 0.784 & 0.770 & 0.858 & 0.758 \\
$1 \mathrm{ft}$ lane widening & 1.098 & 1.333 & 1.242 & 1.351 \\
$2 \mathrm{ft}$ lane widening & 1.205 & 1.778 & 1.542 & 1.825 \\
\hline
\end{tabular}

(b) Model 2

\begin{tabular}{ccccc}
\hline \multirow{2}{*}{ Treatments } & \multicolumn{2}{c}{ All crash type } & \multicolumn{2}{c}{ Lane-departure crashes } \\
\cline { 2 - 5 } & All & Fatal and Injury & All & Fatal and Injury \\
\hline $\begin{array}{c}\text { Asphalt resurfacing } \\
\text { Adding } 2 \mathrm{ft} \text { paved shoulders with shoulder } \\
\text { rumble strips }\end{array}$ & 0.399 & 0.388 & 1.267 & 1.360 \\
Adding 2 $\mathrm{ft}$ paved shoulders & 0.745 & 0.516 & 0.766 & 0.536 \\
\end{tabular}

Table 4. Estimated Safety effectiveness of multiple treatments using before-and-after EB method.

\begin{tabular}{|c|c|c|c|c|c|c|c|c|}
\hline \multicolumn{9}{|c|}{ (a) Safety effectiveness of safety edge treatment with lane widening } \\
\hline \multirow{2}{*}{ Crash Type } & \multirow{2}{*}{ Severity } & \multicolumn{2}{|c|}{ Crashes in after period } & \multirow{2}{*}{$\begin{array}{l}\text { CMF for } \\
\text { combined } \\
\text { treatments }\end{array}$} & \multirow{2}{*}{ SE } & \multirow{2}{*}{$95 \% \mathrm{CI}$} & \multirow{2}{*}{$\%$ Reduction } & \multirow{2}{*}{ Significance } \\
\hline & & Observed & EB estimate & & & & & \\
\hline \multirow[b]{2}{*}{ All } & All & 29 & 50 & 0.51 & 0.115 & $(0.29,0.74)$ & 49 & Significant at $95 \% \mathrm{CI}$ \\
\hline & $\begin{array}{c}\text { Fatal and } \\
\text { injury }\end{array}$ & 7 & 11 & 0.6 & 0.240 & $(0.13,1.07)$ & 40 & Not significant at $90 \% \mathrm{CI}$ \\
\hline \multirow[b]{2}{*}{ Lane-departure } & All & 24 & 17 & 0.65 & 0.177 & $(0.30,1.00)$ & 35 & Significant at $90 \% \mathrm{CI}$ \\
\hline & $\begin{array}{c}\text { Fatal and } \\
\text { injury }\end{array}$ & 3 & 6 & 0.53 & 0.312 & $(0,1.14)$ & 47 & Not significant at $90 \% \mathrm{CI}$ \\
\hline \multicolumn{9}{|c|}{ (b) Safety effectiveness of adding $2 \mathrm{ft}$ paved shoulders with asphalt resurfacing and/or shoulder rumble strips } \\
\hline \multirow{2}{*}{ Crash Type } & \multirow{2}{*}{ Severity } & \multicolumn{2}{|c|}{ Crashes in after period } & \multirow{2}{*}{$\begin{array}{l}\text { CMF for } \\
\text { combined } \\
\text { treatments }\end{array}$} & \multirow{2}{*}{ SE } & \multirow{2}{*}{$95 \% \mathrm{CI}$} & \multirow{2}{*}{ \% Reduction } & \multirow{2}{*}{ Significance } \\
\hline & & Observed & EB estimate & & & & & \\
\hline \multirow[b]{2}{*}{ All } & All & 655 & 684 & 0.96 & 0.046 & $(0.87,1.05)$ & 4 & Not significant at $90 \% \mathrm{CI}$ \\
\hline & $\begin{array}{c}\text { Fatal and } \\
\text { injury }\end{array}$ & 146 & 211 & 0.69 & 0.064 & $(0.56,0.82)$ & 31 & Significant at $95 \%$ CI \\
\hline \multirow[b]{2}{*}{ Lane-departure } & All & 187 & 341 & 0.55 & 0.045 & $(0.46,0.64)$ & 45 & Significant at $95 \%$ CI \\
\hline & $\begin{array}{l}\text { Fatal and } \\
\text { injury }\end{array}$ & 75 & 140 & 0.53 & 0.067 & $(0.40,0.66)$ & 47 & Significant at $95 \%$ CI \\
\hline
\end{tabular}

However, the estimated CMFs for adding $2 \mathrm{ft}$ paved shoulders with asphalt resurfacing and/or shoulder rumble strips are significant at $95 \%$ confidence interval except for all crashes. Since Table 4 shows the estimated CMFs for the combined treatments. Finally, the individual CMFs were calculated using Equation (7), (8), and (9).

\subsection{Estimated Individual CMFs}

Since the main focus was to identify the safety effectiveness of safety edge treat- 
ment and adding $2 \mathrm{ft}$ paved shoulders, individual CMFs were calculated for those two treatments. However, the CMFs for lane widening and asphalt resurfacing on two-lane undivided road segments were not available for Kansas. Therefore, it was decided to use CMFs estimated from regression method for considered road segments. Even though the CMFs for shoulder rumble strips on rural two-lane road segments are available for Kansas those provide an average crash reduction due to shoulder rumble strips on similar road segments. The safety effectiveness of the shoulder rumble strips on considered road segments can be within the $95 \%$ confidence interval of the respective CMF. Therefore, it was decided to use the estimated CMFs developed using regression parameters which are presented in Table 3. Table 5 shows the calculated individual CMFs for safety edge treatment and adding $2 \mathrm{ft}$ paved shoulders on considered road segments.

It is seen that the individual CMFs estimated for all crashes from regression method shown in Table 3(a) is similar to CMFs estimated for safety edge treatments on the road segments with $1 \mathrm{ft}$ lane widening using method 3 shown in Table 5(a). For the fatal and injury all crash types and lane-departure crashes, CMFs estimated from regression method in Table 3(a) is similar to the individual CMFs calculated using method 2 shown in Table 5(a) for the safety edge treatments on the road segments with $2 \mathrm{ft}$ lane widening.

Considering the result in Table 5(b), it can be seen that the method 3 gave similar results for the CMFs calculated for all crashes and injury using regression method in Table 3(a). Method 2 and 3 gave the similar results for the CMF estimated for all lane-departure crashes and fatal and injury all crash types. However, it should be noted that this research was done to estimate CMFs due to individual treatment, not to find the relationship between individual treatments to the combined treatments. Therefore, having similar but not the exact CMFs are understandable since the emphasis was not given to identify the exact relationship of individual CMFs to the combined CMFs.

Furthermore, the results showed that adding only the $2 \mathrm{ft}$ shoulders have significantly increased all crashes and fatal and injury crashes throughout these years. However, the results showed that adding $2 \mathrm{ft}$ paved shoulders reduces lane-departure crashes on particular road segments. Furthermore, results showed that asphalt resurfacing reduce all crashes but increase lane-departure crashes. Finally, it is seen that adding $2 \mathrm{ft}$ paved shoulders with rumble strips have a significant safety effectiveness than adding $2 \mathrm{ft}$ paved shoulders without rumble strips.

\section{Conclusions}

Developing CMFs using before-and-after EB method is one of the widely used practices among the safety engineers to identify the safety effectiveness of treatment or multiple treatments. However, it is required to use additional methods to determine the individual safety effectiveness of the combined treatments, and 
Table 5. Estimated CMFs for individual treatments.

(a) Individual CMFs estimated for safety edge treatment

\begin{tabular}{|c|c|c|c|c|c|c|c|c|}
\hline & \multicolumn{4}{|c|}{ All crashes } & \multicolumn{4}{|c|}{ Lane-departure crashes } \\
\hline & \multicolumn{2}{|c|}{ All } & \multicolumn{2}{|c|}{ Fatal and injury } & \multicolumn{2}{|c|}{ All } & \multicolumn{2}{|c|}{ Fatal and injury } \\
\hline${ }^{\mathrm{a} C o m b i n e d ~ C M F}\left(\mathrm{CMF}_{\mathrm{CT}}\right)$ & \multicolumn{2}{|c|}{0.51} & \multicolumn{2}{|c|}{0.6} & \multicolumn{2}{|c|}{0.65} & \multicolumn{2}{|c|}{0.53} \\
\hline${ }^{\mathrm{b}} \mathrm{CMF}$ for increasing lane width $\left(\mathrm{CMF}_{2}\right)$ & $1.101^{*}$ & $1.21^{\star}$ & $1.331^{*}$ & $1.782^{*}$ & $1.241^{*}$ & $1.542^{*}$ & $1.351^{*}$ & $1.832^{*}$ \\
\hline Method 1: ${ }^{c} \mathrm{CMF}$ for safety edge $\left(\mathrm{CMF}_{1}\right)$ & $0.463^{*}$ & $0.424^{*}$ & $0.453^{*}$ & $0.344^{*}$ & $0.523^{*}$ & $0.424^{*}$ & $0.393^{*}$ & $0.294^{*}$ \\
\hline Method 2: ${ }^{c} \mathrm{CMF}$ for safety edge $\left(\mathrm{CMF}_{1}\right)$ & $0.533^{*}$ & $0.564^{*}$ & $0.703^{*}$ & $0.834^{*}$ & $0.733^{*}$ & $0.834^{*}$ & $0.623^{*}$ & $0.754^{*}$ \\
\hline Method 3: ${ }^{\mathrm{c}} \mathrm{CMF}$ for safety edge $\left(\mathrm{CMF}_{1}\right)$ & $0.783^{*}$ & $0.684^{*}$ & $0.553^{*}$ & $0.414^{*}$ & $0.553^{*}$ & $0.444^{*}$ & $0.593^{*}$ & $0.444^{*}$ \\
\hline
\end{tabular}

(b) Individual CMFs estimated for adding $2 \mathrm{ft}$ paved shoulders

\begin{tabular}{|c|c|c|c|c|}
\hline & \multicolumn{2}{|c|}{ All crashes } & \multicolumn{2}{|c|}{ Lane-departure crashes } \\
\hline & All & Fatal and injury & All & Fatal and injury \\
\hline${ }^{\mathrm{a}}$ Combined $\mathrm{CMF}\left(\mathrm{CMF}_{\mathrm{CT}}\right)$ & 0.96 & 0.69 & 0.55 & 0.53 \\
\hline${ }^{\mathrm{b}} \mathrm{CMF}$ for rumbl strips $\left(\mathrm{CMF}_{2}\right)$ & 0.75 & 0.52 & 0.77 & 0.54 \\
\hline $\mathrm{b}^{*} \mathrm{CMF}$ for resurfacing road $\left(\mathrm{CMF}_{2}\right)$ & 0.40 & 0.39 & 1.27 & 1.36 \\
\hline Method 1: ${ }^{\mathrm{c}} \mathrm{CMF}$ for adding $2 \mathrm{ft}$ paved shoulders $\left(\mathrm{CMF}_{1}\right)$ & 3.20 & 3.40 & 0.56 & 0.72 \\
\hline $\begin{array}{l}\text { Method 2: 'CMF for for adding } 2 \mathrm{ft} \text { paved shoulders } \\
\qquad\left(\mathrm{CMF}_{1}\right)\end{array}$ & 1.42 & 1.06 & 0.59 & 0.65 \\
\hline Method 3: ${ }^{\mathrm{c}} \mathrm{CMF}$ for adding $2 \mathrm{ft}$ paved shoulders $\left(\mathrm{CMF}_{1}\right)$ & 1.17 & 1.14 & 0.33 & 0.36 \\
\hline
\end{tabular}

Note: ${ }^{\mathrm{C}} \mathrm{CMFs}$ were estimated using before-and-after EB method. ${ }^{\mathrm{b}} \mathrm{CMFs}$ were estimated using regression parameters for increasing lane width in Table 2. ${ }^{\mathrm{C}} \mathrm{CMFs}$ were estimated using the methods shown in Equation (7), (8) and (9). ${ }^{1 *} \mathrm{CMFs}$ for $1 \mathrm{ft}$ lane widening, ${ }^{2 *} \mathrm{CMFs}$ for $2 \mathrm{ft}$ lane widening. ${ }^{3 *} \mathrm{CMFs}$ for safety edge treatment on the road segments which had $1 \mathrm{ft}$ lane widening. ${ }^{4} \mathrm{CMFs}$ for safety edge treatment on the road segments which had $2 \mathrm{ft}$ lane widening.

some of the widely used methods are provided in Equation (7), (8) and (9). It is unclear which method is to be used for given geographic region. Therefore, this study employed an alternative method based on regression models to estimate individual CMFs where multiple treatments have been implemented at the same time. This method has many advantages and some limitations which should be addressed in the future research.

One of the advantages is that if the considered treatment was implemented with another treatment(s), this approach could be used to identify the individual safety effectiveness of each treatment. Hence decisions can be made whether to implement these treatments individually or collectively. Even though there are some methods to account for the multiple treatments as shown in Equation (7), (8) and (9), those methods require the CMFs of other treatments which might be not available for given region, facility type or considered crash types. In such case, this method can be implemented directly which does not require CMFs for other treatment implemented at the same time to the treatment of interest. Even though CMFs are available for the other treatments, those are average safety effectiveness of the specific treatment on similar road segments, but not necessarily the same on the considered road segments. Therefore, the regression method 
will estimate the safety effectiveness of other treatments specific to the considered road segments. Since many explanatory variables are considered when developing the regression models, they will also act as the SPFs in EB method and will provide accurate crash predictions. Since the models are developed using same road segments by assigning before and after characteristics, the effect of the confounding variables which are not included into crash frequency models such as drivers' culture, demographic distribution of the drivers and land use pattern, can be minimized.

Even though there are many advantages of using this regression approach to estimate individual CMFs, there are some limitations which needed to be addressed in future research. Since this approach requires regression modeling, it is necessary to have enough sample size. If the sample size is small, the developed regression model will have larger p-values for the important explanatory variables such as the treatment as in the Model 1 . If the sample size is relatively large, p-values will be smaller; hence the important variables become significant at higher confidence intervals as in the Model 2. Furthermore, if the considered road segments have crash distribution with a narrow range, the developed models using such samples tend to give larger p-values as in the fatal and injury crash models. However, in both Model 1 and 2, the standard error of the treatment which is the CMF is larger than in the respective EB method. Therefore, it is necessary to find out the optimum sample size for such models which give significant p-values with lower standard errors. Finally, this method is not useful if the treatments were not implemented at the same time.

\section{Acknowledgements}

The authors would like to thank Mr. Steven Buckley and Ms. Elsit Mandal from KDOT for providing information on the countermeasures and the traffic and geometric data of Kansas roadways. Furthermore, thanks go to Mr.Greg Schieber, Mr.Troy Howard, Mr. Wayne Gudmonson, Ms. Donna Schmit, Mr. Hugh Bogle and Mr. Jeff Stewart, area engineers from KDOT for providing the information on safety edge treatments and adding $2 \mathrm{ft}$ paved shoulders.

\section{Conflicts of Interest}

The authors declare no conflicts of interest regarding the publication of this paper.

\section{References}

[1] World Health Organization (2013) Violence, Injury Prevention, and World Health Organization. Global Status Report on Road Safety 2013: Supporting a Decade of Action.

[2] Insurance Institute for Highway Safety Highway Loss Data Institute (2016) Fatality Facts.

http://www.iihs.org/iihs/topics/t/general-statistics/fatalityfacts/state-by-state-overvi ew/2015 
[3] NHTSA (2016) Fatality Analysis Reporting System. http://www-fars.nhtsa.dot.gov/Main/index.aspx

[4] Kansas Department of Transportation (2015) Kansas Strategic Highway Safety Plan. http://www.ksdot.org/Assets/wwwksdotorg/bureaus/burTrafficSaf/reports/reportsp df/SHSP2015.pdf

[5] Highway Safety Manual (2010) American Association of State Highway and Transportation Officials (AASHTO), Washington DC.

[6] Zeng, H., Schrock, S.D. and Mulinazzi, T. (2013) Evaluation of Safety Effectiveness of Composite Shoulders, Wide Unpaved Shoulders, and Wide Paved Shoulders in Kansas. K-TRAN: KU-11-1, Kansas Department of Transportation.

[7] Lan, B., Persaud, B., Lyon, C. and Bhim, R. (2009) Validation of a Full Bayes Methodology for Observational Before-after Road Safety Studies and Application to Evaluation of Rural Signal Conversions. Accident Analysis \& Prevention, 41, 574-580. https://doi.org/10.1016/j.aap.2009.02.010

[8] Hauer, E. (1997) Observational Before-After Studies in Road Safety-Estimating the Effect of Highway and Traffic Engineering Measures on Road Safety. Elsevier Science Incorporated, Tarrytown, NY.

[9] Persaud, B. and Lyon, C. (2007) Empirical Bayes Before-After Safety Studies: Lessons Learned from Two Decades of Experience and Future Directions. Accident Analysis \& Prevention, 39, 546-555. https://doi.org/10.1016/j.aap.2006.09.009

[10] Gross, F. and Hamidi, A. (2011) Investigation of Existing and Alternative Methods for Combining Multiple CMFs, Highway Safety Improvement Program Technical Support. T-06-013, 1-45.

[11] Park, J., Abdel-Aty, M. and Lee, C. (2014) Exploration and Comparison of Crash Modification Factors for Multiple Treatments on Rural Multilane Roadways. Accident Analysis \& Prevention, 70, 167-177. https://doi.org/10.1016/j.aap.2014.03.016

[12] Turner, B. (2011) Estimating the Safety Benefits When Using Multiple Road Engineering Treatments. Road Safety Risk Reporter, 11.

[13] Hallmark, S.L., Veneziano. D., McDonald, T., Graham, J., Bauer, K.M., Patel, R. and Council, F.M. (2006) Safety Impacts of Pavement Edge Drop-Offs. Center for Transportation Research and Education, Iowa State University, Ames.

[14] Hallmark, S., McDonald, T., Sperry, B. and Vencil, E. (2011) Evaluation of Safety Edge Benefits in Iowa. Trans Project 09-358, Center for Transportation Research and Education, Iowa State University, Ames.

[15] Hallmark, S.L., Goswamy, A. and Pawlovich, M.D. (2016) Safety Edge Crash Modification Factors. Institute for Transportation, Iowa State University, Ames.

[16] Graham, J., Richard, K., O’Laughlin, M. and Harwood, D. (2011) Safety Evaluation of the Safety Edge Treatment. FHWA-HRT-11-024, Federal Highway Administration, McLean.

[17] Labi, S. (2011) Efficacies of Roadway Safety Improvements across Functional Subclasses of Rural Two-Lane Highways. Journal of Safety Research, 42, 231-239. https://doi.org/10.1016/j.jsr.2011.01.008

[18] Abdel-Aty, M., Lee, C., Park, J., Wang, J., Abuzwidah, M. and Al-Arifi, S. (2014) Validation and Application of Highway Safety Manual (Part D) in Florida. BDK78-977-14, Florida Department of Transportation, Tallahassee.

[19] Galgamuwa, U. and Dissanayake, S. (2018) Evaluation of the Safety Effectiveness of Lane-Departure Countermeasures on Two-Lane Undivided Roadways Using Crash Modification Factors. Journal of Transportation Safety \& Security, 1-21. 
[20] Bamzai, R., Lee, Y. and Li, Z. (2011) Safety Impacts of Highway Shoulder Attributes in Illinois. FHWA-ICT-11-078, Illinois Department of Transportation, Urbana.

[21] Abdel-Aty, M., Devarasetty, P.C. and Pande, A. (2009) Safety Evaluation of Multilane Arterials in Florida. Accident Analysis \& Prevention, 41, 777-788. https://doi.org/10.1016/j.aap.2009.03.015

[22] Erwin, T.C. (2007) Safety Effects of Preventative Maintenance: Microsurfacing-A Case Study.

[23] Russell, E.R., Rys, M.J. and Brin, T.S. (2003) US Experience with Centerline Rumble Strips on Two-Lane Roads: Pattern Research and North American Usage. ARRB Transport Research.

[24] Poch, M. and Mannering, F. (1996) Negative Binomial Analysis of Intersection-Accident Frequencies. Journal of Transportation Engineering, 122, 105-113. https://doi.org/10.1061/(ASCE)0733-947X(1996)122:2(105)

[25] Gross, F. and Donnell, E.T. (2011) Case-Control and Cross-Sectional Methods for Estimating Crash Modification Factors: Comparisons from Roadway Lighting and Lane and Shoulder Width Safety Effect Studies. Journal of Safety Research, 42, 117-129. https://doi.org/10.1016/j.jsr.2011.03.003

[26] Montgomery, D.C., Peck, E.A. and Vining, G.G. (2015) Introduction to Linear Regression Analysis. John Wiley \& Sons, Hoboken.

[27] Belsley, D.A., Kuh, E. and Welsch, R.E. (2005) Regression Diagnostics: Identifying Influential Data and Sources of Collinearity. John Wiley \& Sons, Hoboken.

[28] SAS Institute (2015) Base SAS 9.4 Procedures Guide. SAS Institute, Cary.

[29] Chen, Y. and Persaud, B. (2014) Methodology to Develop Crash Modification Functions for Road Safety Treatments with Fully Specified and Hierarchical Models. Accident Analysis \& Prevention, 70, 131-139. https://doi.org/10.1016/j.aap.2014.03.012

[30] Galgamuwa, U. and Dissanayake, S. (2018) Safety Effectiveness of Chevrons and Post-Mounted Delineators in Reducing Lane-Departure Crashes. International Conference on Transportation and Development, Pittsburgh, 15-18 July 2018.

[31] Gross, F., Persaud, B. and Lyon, C. (2010) A Guide to Developing Quality Crash Modification Factors. FHWA-SA-10-032, Federal Highway Administration.

[32] Galgamuwa, U. (2018) Estimating Crash Modification Factors for Lane-Departure Countermeasures in Kansas. Ph.D., Kansas State University, Manhattan.

[33] Devasurendra, K., Perera, L. and Bandara, S. (2017) An Insight to Motorized Two and Three Wheel Crashes in Developing Countries: A Case Study in Sri Lanka. Journal of Transportation Safety \& Security, 2017, 204-215. https://doi.org/10.1080/19439962.2016.1236052

[34] Dissanayake, S. and Perera, L. (2011) A Survey Based Study of Factors Related to Older Driver Highway Safety. Journal of Transportation Safety \& Security, 3, 77-94. https://doi.org/10.1080/19439962.2010.537437 